\title{
Advanced Approaches to the Visualization of Data Characterizing Distribution Features of Alien Plant Species
}

\author{
V. K. Tokhtar* \\ Belgorod State National Research University, Belgorod, 308015 Russia \\ *e-mail:tokhtar@bsu.edu.ru \\ Received November 14, 2017
}

\begin{abstract}
Results of application of different approaches to the data visualization during the study of alien plant species have been analyzed and summarized, and the prospects of their use for different purposes have been evaluated. The existing experience in the study of alien plant species shows that traditional methods used to analyze their composition and distribution patterns in different regions are informative only for determining the main tendencies reflecting global processes of a phytobiota synanthropization. At the same time, new state-of-art methods are required to reveal the latent patterns of plant migration and the processes of their naturalization. The most promising approaches to analyzing large volumes of data are multivariate statistical methods. The potential of these methods is determined by their capability to identify relationships between a wide range of floristic and biological data and environmental characteristics, which can be visualized. These methods allow us to present different data in the form of diagrams reflecting interactions between individual species or whole groups of alien plants and climatic or environmental variables. They make it possible to create models of expansion of invasive species. They reflect the current statistical distances and relationships between different objects of study, which makes it possible to identify features of the group strategy of colonization of various natural and/or technogenic habitats by alien species. These strategies depend mainly on the biological characteristics of species, level of anthropogenic transformation of a regional flora, and environmental parameters.
\end{abstract}

Keywords: invasion, alien species, multivariate statistical methods, data visualization

DOI: $10.1134 / \mathrm{S} 2075111718030153$

\section{INTRODUCTION}

The influence of alien organisms on the flora, fauna, and the society as a whole takes on a global significance, since now the problem of their global expansion can be solved only at the international level. Expansion of nonindigenous organisms does not depend on state borders, so local measures are no longer efficient and require some efforts of international organizations (Tokhtar, 2016). Invasive species cause huge economic losses. Invasion of adventitious species into the United States, India, and Brazil results in annual losses of 137, 117, and 50 billion US dollars, respectively (Vinogradova et al., 2010).

Import and expansion of alien species poses a direct threat to the existence of indigenous species, while yield losses caused by weeds, many of which represent adventitious species, may reach 9-30\%. Biological invasion of alien plant species is of a global character and reduces natural biodiversity. In addition, the relevancy of a study of alien species is determined by either their economic value or, on the contrary, their harmfulness as invasive species replacing indigenous ones. Thus, today one of the most import- ant theoretical issues in the study of alien plant species is a determination of basic patterns of their expansion depending on a complex of natural and anthropogenic factors. The solution of this problem may be significantly simplified using methods providing visualization of large volumes of heterogeneous data. In this study, we analyzed and generalized results of the use of various analytic and data visualization approaches to the study of alien plant species and evaluated the prospects of their use for different purposes.

\section{MATERIALS AND METHODS}

The model objects of our study were both separate species widespread throughout different continents (Ambrosia artemisiifolia L., Conyza canadensis L., and species of the genus Oenothera L. (subsect. Oenothera, Onagraceae)) and groups of alien species migrating into different types of natural and anthropogenically disturbed habitats. The first two of the listed species are characterized by a wide ecological range manifested during their intercontinental invasions. Oenothera species are actively expanding in Europe and are 
characterized by intense speciation and microevolution processes occurring in their populations (Renner, 1917; Hudziok, 1968; Gutte and Rostanski, 1971; Soldano, 1979; Jehlik and Rostanski, 1995). Therefore, this genus is a good model for tracing features of the expansion and microevolution of different phylogenetically isolated plant groups in Europe (Tokhtar et al., 2011).

During the study of alien species, we summarized a large volume of original, published, and herbarium materials on the chorology of Oenothera species in Western and Eastern Europe and on the distribution of Ambrosia artemisiifolia and Conyza canadensis in different parts of Europe. We studied numerous plant habitats in Germany (North Rhine-Westphalia, Hesse, Baden-Württemberg federal states), France (Alsace), Czech Republic, Slovakia, Poland, Ukraine, and Russia (Wittig et al., 1999; Wittig and Tokhtar, 2002, 2003; Rostański et al., 2004). We also analyzed herbarium materials from the Komarov Botanical Institute of the Russian Academy of Sciences (St. Petersburg, Russia, LE), Tsitsin Main Botanical Garden of the Russian Academy of Sciences (Moscow, Russia, MHA), Moscow State University (Moscow, Russia, MW), Moscow State Pedagogical University (Moscow, Russia, MOSP), Southern Federal University (Rostov-on-Don, Russia, RV), Institute of Botany of the National Academy of Sciences of Ukraine (Kyiv, Ukraine, KW), Donetsk Botanical Garden of the National Academy of Sciences of Ukraine (Donetsk, Ukraine, DNZ), University of Silesia (Katowice, Poland, KTU), Institute of Botany of the Czech Academy of Sciences (Prühonice, Czech Republic, PR), Berlin-Dahlem Botanical Garden (Berlin, Germany, B), Sekenbergianum Museum (Frankfurt am Main, Germany, SNG), and Museum of Natural History (Wiesbaden, Germany).

Studying the distribution of alien species in natural and technogenic habitats of the southwestern part of the Central Russian Upland, we tested both traditional methods of florogenetic analysis and multivariate statistical methods, such as discriminant analysis, factor analysis, principal component analysis, correspondence analysis, and canonical correspondence analysis (Chibrik and El'kin, 1991; Ter Braak, 1995; Tokhtar, 2016; Tokhtar et al., 2017). Correlation structures of morphological traits were analyzed according to methods developed by Rostova (2000).

Evaluation of the lists of alien plant species in technogenic and natural habitats was carried out on the basis of correlation matrices; for each pair of floras, Jaccard's coefficients or Spearman's rank correlation coefficients (in the case of evaluation of plant communities and their species richness) were calculated. Data visualization was performed by the arrangement of the obtained correlation matrices in a factor space and their treatment with the Microsoft Excel XP, Statistica 6.0, Canoco for Windows 4.02, CanoDraw 3.1, and CanoPost 1.0 program packages.

\section{RESULTS AND DISCUSSION}

To date, a large number of methods intended to evaluate the processes of a flora adventization and the success of invasions of alien species have been developed. Some of these methods are based on traditional approaches representing results of the taxonomic and typological analysis of the structures of invasive flora fractions, whereas other methods are based on statistical data analysis.

Use of any methods intended to study plant invasions is determined by a general problem statement and the scale of studies. Unfortunately, in many Russian publications devoted to the revelation of alien plant species, the problem of factor determination is usually not considered.

Many popular spatial and statistical methods of study of alien species, such as GIS modeling, Bioclim, and Domain, are based on a probabilistic, i.e., potential location of a particular species in new habitats depending on the suitability of local climatic conditions of these areas for its growth. For example, study of Ambrosia artemisiifolia L. based on this principle provided a design of two slightly differing forecast models of expansion of this species in Europe (Pasierbiński et al., 2011). Inaccuracy of such models is determined by the fact that successful invasion of alien species into plant communities significantly depends on the competitive abilities of plants, relations between the components of a community, and the resistance of local phytocoenoses to invasions (Pasierbiński et al., 2011). In addition, models based only on climatic parameters do not take into account the effect of anthropogenic factors, though in many cases they provide a critical influence on the character and intensity of a species expansion. Thus, climatic modeling of a habitat of alien species makes it possible to determine only potential capabilities of a plant for expansion and often provides different results. Therefore, the development of models based only on this principle requires an accurate and selective approach.

Development and application of data visualization methods is now very important for the explanation of the features of expansion of alien species and the construction of forecasting models. A choice of data visualization methods during the study of alien species expansion depends on the following factors:

(1) Object of study. It may represent (a) separate species, (b) affiliated (related) groups of species (taxa), and (c) groups of phylogenetically distant species characterized by associated migration.

(2) Gradient of analysis. It may be geographical or ecological (for example, colonization of ecotopes by adventitious species along the "technogenic habitatnatural habitat" gradient or processes occurring in the opposite direction (if it is necessary to reveal features of the expansion of such species into toxic technogenic ecotopes)). 


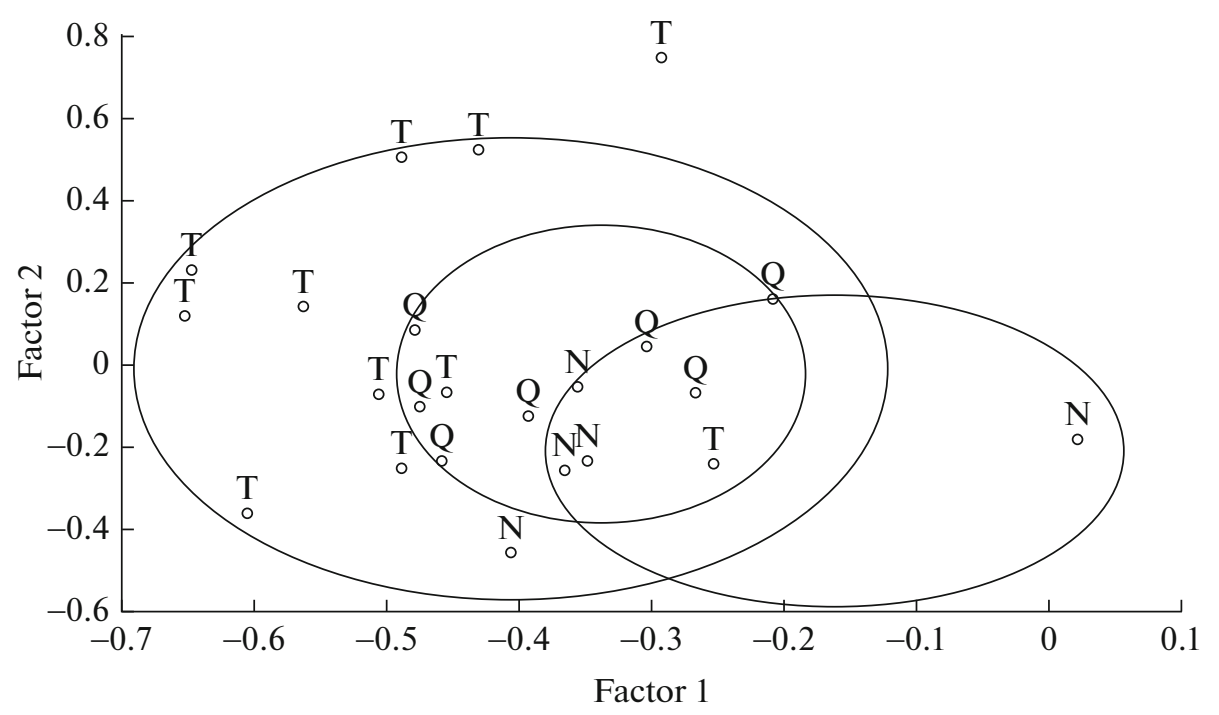

Fig. 1. Visualization of correlation structures of quantitative morphological traits of Conyza canadensis populations obtained by a principal component analysis. Letter symbols indicate population structures in technogenic (T), quasi-natural (Q), and natural (N) ecotopes. One point reflects a correlation structure of 18 traits for each population.

(3) Problem of the development of a certain model of species expansion.

Analysis of our results shows that invasion mechanisms may be revealed by combining traditional and statistical research methods, which supplement each other and make it possible to analyze complex and multilateral relations between ecological and biological features of species and climatic and ecological environmental factors (Tokhtar and Fomina, 2011).

Visualization of morphological differences between geographically distant populations of the same species may be achieved by a discriminant analysis, which is often used for these purposes. In the case of such differences in the structure of local populations of the same region, which are formed along ecologically conditioned gradients, the use of a principal component analysis providing visualization of structures of trait correlations for different alien plant populations is preferable.

We ascertained that the mean values of trait correlations and correlation matrices of Conyza canadensis populations arranged in the factor space change as the anthropogenic influence increases (Tokhtar and Mazur, 2011) (Fig. 1). Populations from technogenic, quasi-natural, and natural ecotopes are arranged in the left, central, and right parts of the diagram, respectively. Taking into account the distribution of correlation structures of populations in the factor space, the first statistical factor is interpreted as a factor of weakening of the anthropogenic impact on populations. These results confirm the data obtained earlier by Rostova (2000) for different species and indicate good prospects for the use of this method for evaluation and visualization of changes occurring in correlation structures of morphological traits depending on the type and intensity of an anthropogenic influence.

According to our studies of affiliated model groups of species, arranged on a model genus Oenothera (subsect. Oenothera L., Onagraceae) and intended to visualize data and to reveal factors determining species expansion (Wittig et al., 1999; Wittig and Tokhtar, 2002, 2003; Tokhtar and Groshenko, 2014), the best results may be obtained in the case of a complex use of both traditional and statistical methods of analysis.

Analysis of data on the species distribution and richness in the anthropogenically transformed model ecotopes of Western and Eastern Europe performed by traditional methods (Wittig and Tokhtar, 2003) revealed a large number of large- and small-flowered species in Western Europe, whereas Eastern Europe was represented mainly by medium-flowered species. The reasons for such distribution of Oenothera species were ascertained by multivariate statistical methods (Tokhtar and Groshenko, 2014).

To study factors limiting the Oenothera distribution, we used a canonical correspondence analysis (Ter Braak, 1995). This method allowed us to visualize the dependences of a species distribution on certain environmental conditions and to determine a spatial location of the centroids of Oenothera ecological niches in Eastern Europe in relation to factors limiting their expansion. As a result, we found that the most active invasive species of Eastern Europe, Oe. biennis, Oe. rubricaulis, and Oe. depressa, are located not far from the center of factors originating from a multidimensional space (Tokhtar and Groshenko, 2014). Therefore, ecological niches of these species are less dependent on most of the analyzed natural and climatic factors (where they have zero values), especially 
temperature conditions and factors of moistening. Ecological niches of species common for Western Europe and rare for Eastern Europe are located within multidimensional space zones corresponding to the values of factors which are typical of wet and warm habitats (Tokhtar and Groshenko, 2014).

Thus, the canonical correspondence analysis allowed us to explain why phylogenetically isolated lines of small- and large-flowered species grow mainly in Western Europe. These species include Oenothera ammophilla, Oe. oakesiana, Oe. glazioviana, Oe. parviflora, and Oe. perangusta. Medium-flowered Oenothera species (Oenothera biennis, Oe. rubricaulis, Oe. depressa, and Oe. hoelscheri) grow everywhere and are observed in Eastern Europe much more frequently than other species. Probably owing to this reason, their frequency and abundance quantitatively decrease in the direction from the western to eastern regions of Europe. On the basis of these results, one may conclude that temperature and moistening conditions represent an important factor influencing on the species composition of Oenothera plants growing in different regions of Europe.

The revelation of distribution patterns for whole groups combining different species, which migrate together into different types of natural (in the case of naturalization) and anthropogenically transformed ecotopes, represents a significantly more complicated problem than the determination of distribution patterns for separate related alien species.

During a study of the colonization of various technogenic (including toxic) habitats with plants, one can state that the efficiency of the use of traditional analytic methods is rather insufficient. Taxonomic and typological ratios between the life forms and biotypes in the structure of such floral complexes are very close, while differences between them are often almost imperceptible. Therefore, it is difficult to make a conclusion about features of their formation and factors influencing on the process of colonization of different types of anthropogenically transformed ecotopes (Tokhtar and Vinogradova, 2009).

The study of groups of alien species formed in different types of technogenic ecotopes performed by the factor analysis of correlation matrices of Jaccard's coefficients showed that colonization of technogenic ecotopes with nonnative species has an ordered character.

Use of factor analysis made it possible to ascertain that alien species colonize different anthropogenic habitats using a group strategy determined by their tolerance to the level of a technogenic influence and degree of anthropogenic transformation of an ecotope. Using multivariate statistical analysis, we determined that adventitious fractions of floras of technogenic ecotopes form three isolated groups in the factor space (Tokhtar and Vinogradova, 2009). These groups are formed under different conditions: (1) nontoxic primarily and secondary technogenic ecotopes;
(2) toxic secondary ecotopes (coking, chemical, and metallurgical plants); (3) toxic primary ecotopes (ashdisposal areas, slag and sludge dumps, mining and processing plants, etc.).

In addition to the factor analysis, one can use canonical correspondence analysis to specify the influence of environmental factors. Using this method, we found that differences in the adventitious species composition of technogenic ecotopes are determined mainly by the action of edaphic factors, such as the soil acidity and fertility. Some of the ecological niches of species are located on the ordination chart near the axis characterizing low humus content in the soil (Tokhtar, 2016). Species able to grow under such conditions show the highest activity during colonization of primary technogenic ecotopes corresponding to these conditions.

Another important task of the study of alien plant expansion is revealing the distribution patterns of invasive species in natural habitats, i.e., naturalization processes accompanied by species introduction into natural communities.

To solve this task, we studied groups of invasive species inhabiting various natural and anthropogenic habitats of the southwestern areas of the Central Russian Upland along the gradient of decrease of the anthropogenic influence: railroads, parks, forests, steppe areas, ravine and gully habitats, chalk outcrops, etc. (Tokhtar et al., 2017).

Jaccard's coefficients and Spearman's rank correlation coefficients (for evaluation of plant communities with allowance for their species abundance) were analyzed for the studied floral complexes. The resulting correlation matrices were arranged in a factor space that provided visualization of the features of alien species expansion in various habitats.

Figures $2 \mathrm{a}$ and $2 \mathrm{~b}$ show that the use of the principal component method resulted in a clear division of invasive species into different groups colonizing steppe and forest habitats. The group of invasive species from chalk outcrops is located separately from the other groups. The distribution of the group of invasive species from ravine and gully ecotopes was wider; species from this group are also observed in the forest, chalk, and anthropogenic (parks and railroads) habitats. This fact is explained by the presence of tree species common to many habitats in the composition of such groups. Anthropogenically transformed ecotopes (parks and railroads) are located close to each other in the factor space owing to the similar composition of invasive species (Figs. 2a, 2b). Plants colonizing steppe habitats are the most isolated. The similarity of species compositions between the listed groups of alien plants colonizing these habitats was determined by a commonness of species marked on the diagram (Figs. 2a, 2b). Within steppe habitats, these species included Amaranthus retroflexus, Cyclachaena xanthiifolia, Conyza canadensis, and Alcea rosea. The major- 


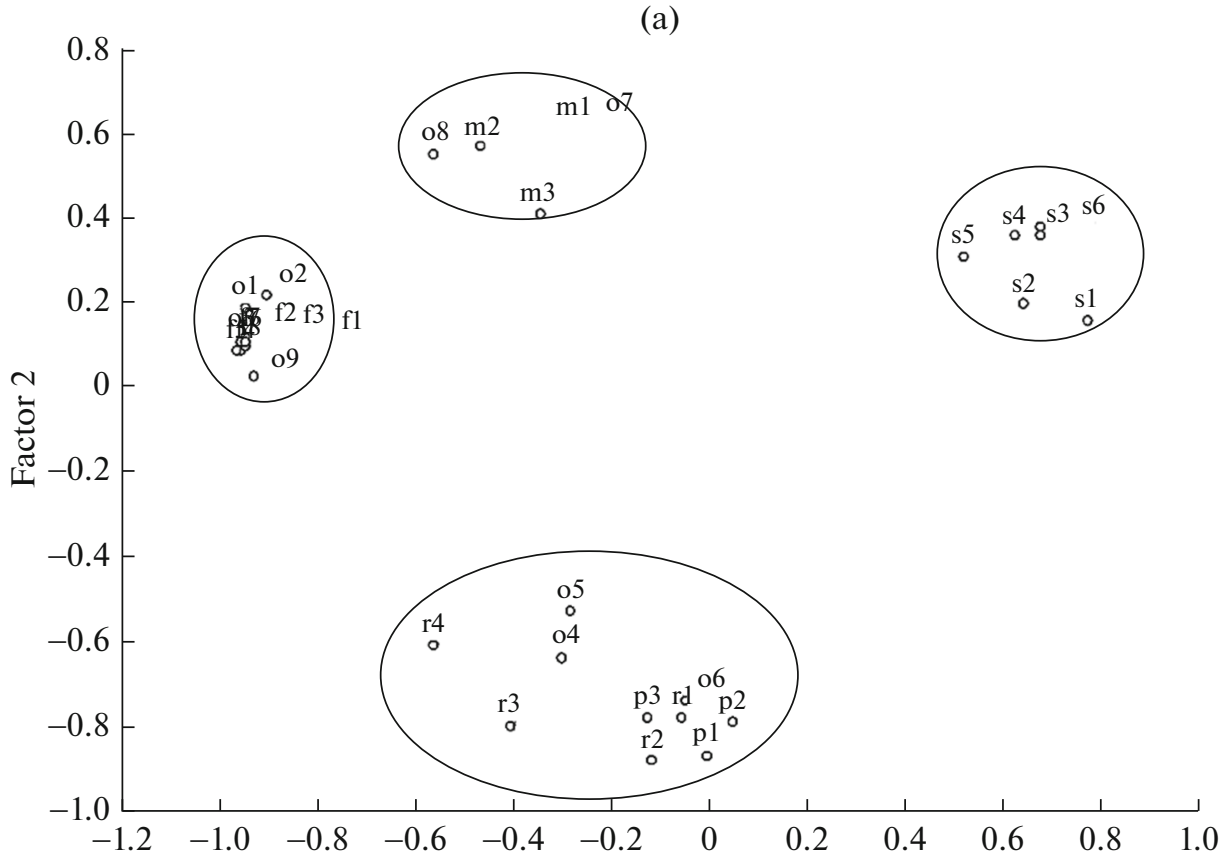

(b)

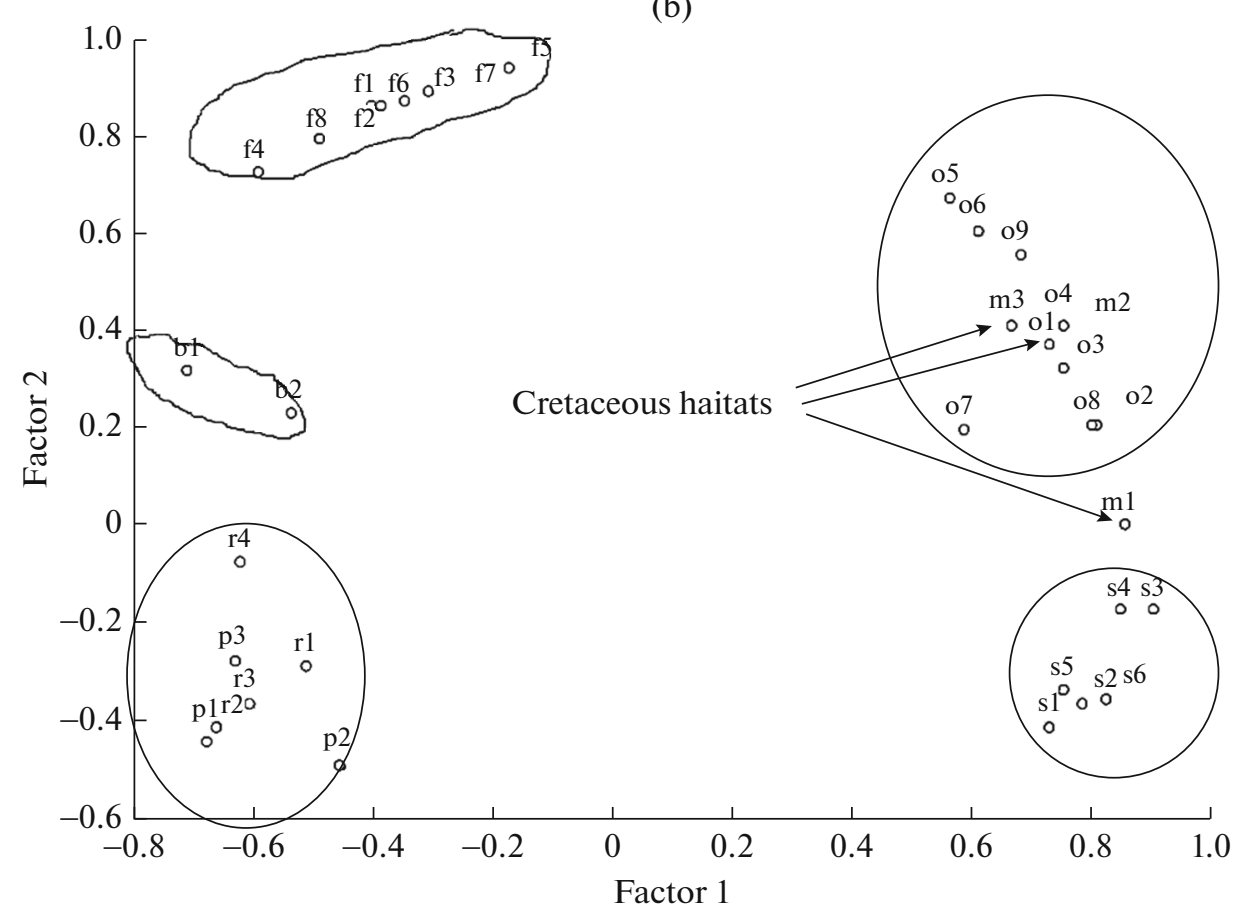

Fig. 2. Distribution of groups of alien species colonizing various natural and anthropogenic ecotopes in the factor space: (a) diagram based on Jaccard's coefficients; (b) diagram based on Spearman's rank correlation coefficients. Designations: b1-b2, marshes; m1$\mathrm{m} 7$, chalk outcrops; $\mathrm{fl}-\mathrm{f8}$, forest habitats; $\mathrm{o} 1-\mathrm{o} 9$, ravine and gully systems; $\mathrm{p} 1-\mathrm{p} 3$, parks; $\mathrm{r} 1-\mathrm{r} 4$, railroads, s1-s6, steppe habitats.

ity of conifer forest ecotopes include species from the genus Oenothera, Robinia pseudoacacia, Acer negundo, Fraxinus pennsylvanica, and Ulmus pumila, whereas broadleaf forest ecotopes include Impatiens parviflora, Arrhenatherum elatius, and Parthenocissus inserta. The similarity of species compositions of invasive plants colonizing chalk outcrop habitats (Fig. 2b) is determined by the presence of Elaeagnus angustifolia, Hippopha rhamnoides, Crataegus monogyna, and Caragana arborescens.

A similar picture was observed during the analysis of a scatter diagram constructed on the basis of Spear- 


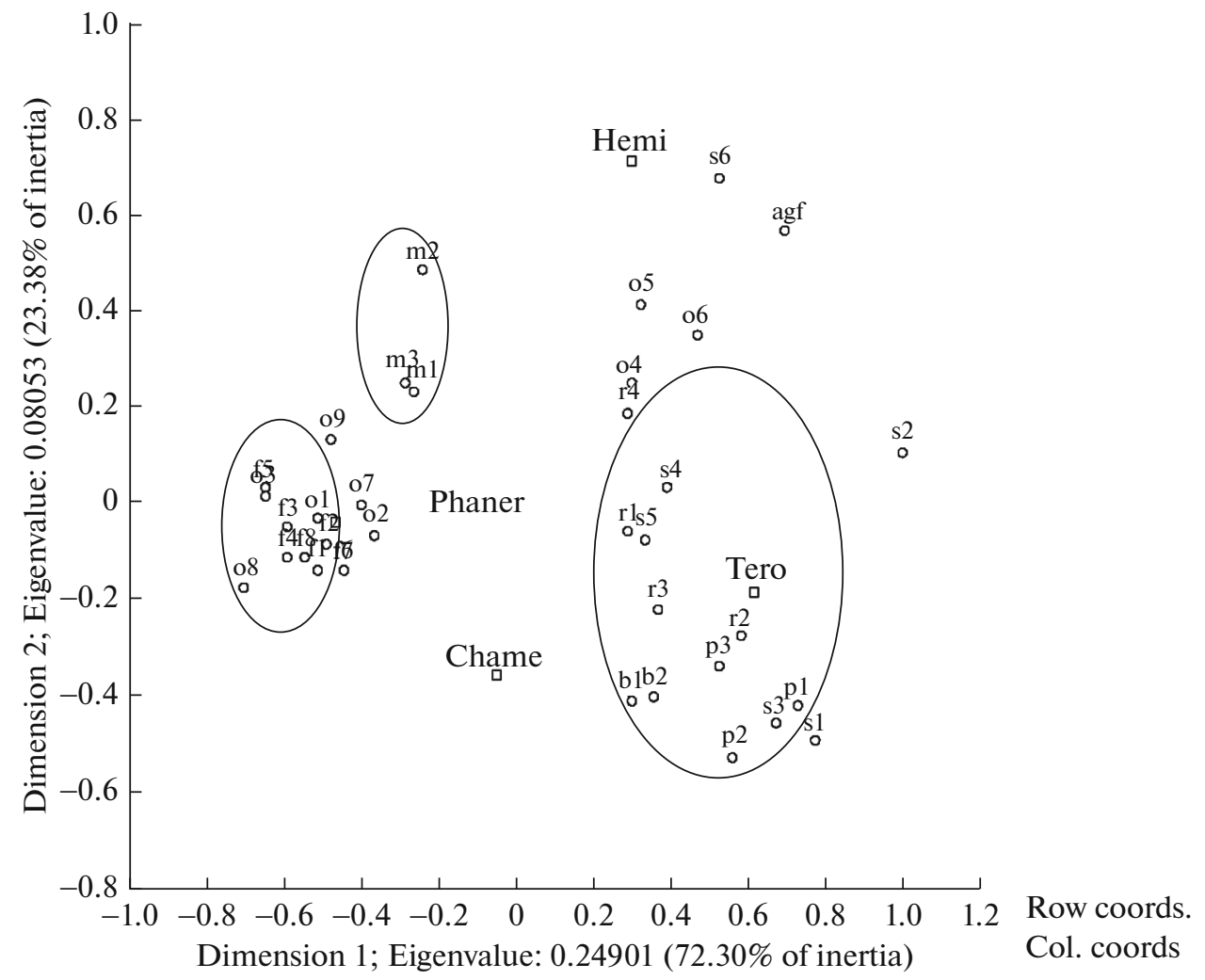

Fig. 3. Visualization of data reflecting proportions of life forms in the groups of alien plants colonizing various habitats, obtained by correlation correspondence analysis. Designations: Hemi, hemicryptophyte; Thero, therophyte; Chame, chamaephyte; Phaner, phanerophyte; b1-b2, marshes; $\mathrm{m} 1-\mathrm{m} 7$, chalk outcrops; f1-f8, forest habitats; o1-o9, ravine and gully systems; 1 1-p3, parks; $r 1-r 4$, railroads, s1-s6, steppe habitats.

man's coefficients with allowance for the abundance of invasive species in plant communities.

The correspondence analysis makes it possible to evaluate the participation of different structural components in coenofloras of various habitats, such as Raunkiær life forms, groups differing in the time of invasion (archaeophytes, kenophytes, or eukenophytes) or invasion status (Fig. 3), etc.

Results presented in Fig. 3 show that points which designate structures of the species composition of alien plants colonizing forest, ravine, and gully habitats are located near the point designating the phanerophyte category. This fact reflects domination of phanerophytes in their structures. Groups of plants growing near railroads and in parks belong to the zone of influence of the "therophyte" category.

Thus, the performed analysis made it possible to visualize structural features of alien plant groups colonizing various ecotopes using correlations between quantitative proportions of different life forms within them. This analysis allows a user to determine the position of each plant group in relation to the studied categories of traits and to reveal their relative positions on the basis of correlative interactions between their structures. In the case of successful explanation of axis values in the factor space via the analysis of significant factor loadings, one can determine not only the level of their influence on alien species groups but also exact distances between them in relation to the acting factors.

\section{CONCLUSIONS}

The potential of the use of multivariate statistical methods is determined by the possibility of a model construction based on the establishment of interrelations between a wide complex of horologic floristic data and environmental characteristics, which can be visualized. Depending on the research tasks, the developed models may be classification, historical (for a study of the dynamics of changes in a species composition), and forecasting.

The examined methods make it possible to evaluate significant volumes of any heterogeneous data using modern software packages and to determine the main factors causing changes in the structure of populations, species, and groups of alien species colonizing ecotopes of different types along various environmental gradients. Depending on factor loadings, statistical factors may be identified. An additional advantage of multivariate statistical methods is the possibility of 
their use to study any correlation matrices and coefficients characterizing the biodiversity and environmental parameters.

Understanding of the processes of expansion of alien species into different natural and anthropogenic habitats requires a deep analysis of internal mechanisms, as well as the development and application of new complex empirical and statistical approaches based on the use of both traditional analysis and multivariate statistical methods to visualize large volumes of data.

The mechanisms of invasions of alien species can be revealed by a combination of traditional and statistical approaches which allow a user to visualize numerous and multilateral relations between the ecological and biological features of species and the climatic and ecological environmental factors.

\section{ACKNOWLEDGMENTS}

This study was financially supported by the Ministry of Education and Science of Russian Federation, state contract no. 6.4854.2017/BCh.

\section{REFERENCES}

Chibrik, T.S. and El'kin, Yu.A., Formirovanie fitotsenozov na narushennykh promyshlennost'yu zemlyakh (Formation of Phytocenoses on Industrial Lands), Sverdlovsk: Ural. Gos. Univ., 1991.

Gutte, P. and Rostanski, K., Die Oenothera-Arten Sachsens, Ber. Arbeitsgem. Sachs. Bot., 1971, no. 9, pp. 63-88.

Hudziok, G., Die Oenothera-Arten der sudlichen Mittelmark und des angrenzenden Flamings, Verh. Bot. Ver. Prov. Brandenb., 1968, vol. 105, pp. 73-107.

Jehlik, V. and Rostanski, K., Notes on the genus Oenothera subsect. Oenothera (Onagraceae) in the Czech Republic, Folia Geobot. Phytotax., 1995, vol. 30, pp. 435-444.

Pasierbiński, A., Zabińska, I., Shevera, M., Tokhtar, V.K., and Tokarska-Guzik, B., The realized niche of Ambrosia artemisiifolia in relation to its potential distribution in Europe, Proc. the 11th Int. Conf. on the Ecology and Management of Alien Plant Invasion "Bridging the Gap between Scientific Knowledge and Management Practice," Szombathely, August 30-September 3, 2011, Abstracts of Papers, Szombathely: Univ. West Hung., 2011, p. 23.

Renner, O., Versuche uber die gametische Konstitution der Oenothera, Z. Abst. Vererb., 1917, vol. 18, pp. 121-294.

Rostański K., Rostański A., Shevera, M., and Tokhtar, V., Oenothera in Ukraine, in The Genus Oenothera L. in Eastern Europe, Cracow: W. Szafer Inst. Bot., 2004.

Rostova, N.S., Variability of morphological traits correlation system. Populations of species of the genus Leucanthemum (Asteraceae) in nature and culture conditions, Bot. Zh., 2000, vol. 85, no. 1, pp. 46-67.

Soldano, A., Per una migliore conoscenza di Oenothera L. subgenere Oenothera in Italia, Atti. Ist. Bot. Lab. Critt. Univ. Pavia, 1979, vol. 13, pp. 145-158.
Ter Braak, C.J.F. and Verdonschot, P.F.M., Canonical correspondence analysis and related multivariate methods in aquatic ecology, Aquat. Sci., 1995, vol. 57, no. 3, pp. 255-289.

Tokhtar, V.K., Regional'naya floristika i sovremennye metody analiza antropogenno transformirovannykh flor (Regional Floristics and Modern Methods of Analysis of Anthropogenically Transformed Floras), Belgorod: Belgorod, 2016.

Tokhtar, V.K. and Fomina, O.V., Features of the formation of urban flora in various natural, climatic, and anthropogenic conditions: factor analysis and visualization of data, Nauch. Ved. Bel. Gos. Univ., Ser. Estest. Nauki, 2011, no. 9 (104), pp. 23-29.

Tokhtar, V.K. and Groshenko, A.S., Differentiation of the climatic niches of the invasive Oenothera L. (subsect. Oenothera, Onagraceae) species in the Eastern Europe, Adv. Environ. Biol., 2014, vol. 8, no. 10, pp. 529-531. https://www.researchgate.net/publication/264041916. Assessed November 7, 2017.

Tokhtar, V.K. and Mazur, N.V., The variability of the correlation structures of the morphological features in Conyza canadensis populations, Nauch. Ved. Bel. Gos. Univ., Ser. Estest. Nauki, 2011, no. 9 (104), pp. 252-256.

Tokhtar, V.K. and Vinogradova, Yu.K., Study of the distribution of alien species in anthropogenically transformed ecotopes by the method of factor analysis, Vestn. Tver. Gos. Univ., Ser. Biol. Ekol., 2009, no. 15, pp. 139-145.

Tokhtar, V.K., Vinogradova, Yu.K., and Groshenko, A.S., Microevolution and invasiveness of Oenothera L. species (subsect. Oenothera, Onagraceae) in Europe, Russ. J. Biol. Invasions, 2011, vol. 2, no. 4, pp. 273-280. https://link. springer.com/article/10.1134/S2075111711040138. Assessed November 7, 2017.

Tokhtar, V.K., Kurskoy, A.Y., Dunaev, A.V., Tokhtar, L.A., and Petrunova, T.V., The analysis of the flora invasive component in the southwest of the Central Russian Upland (Russia), Int. J. Green Pharm., 2017, vol. 11, no. 3, p. S632. http://www.greenpharmacy.info/index.php/ ijgp/article/view/1186/721. Assessed November 7, 2017.

Vinogradova, Yu.K., Maiorov, S.R., and Khorun, L.V., Chernaya kniga flory Srednei Rossii. Chuzherodnye vidy rastenii v ekosistemakh Srednei Rossii (Black Book of the Flora of Central Russia: Alien Plant Species in Central Russian Ecosystems), Moscow: GEOS, 2010.

Wittig, R. and Tokhtar, V.K., Oenothera-Arten auf industriebrachen im westfalischen Ruhrgebiet, Nat. Heimat, 2002, vol. 62, no. 1, pp. 29-32.

Wittig, R. and Tokhtar, V., Die Haufigkeit von OenotheraArten im westlichen Mitteleuropa, Feddes Repert., 2003, vol. 114, nos. 5-6, pp. 372-379.

Wittig, R., Lenker, K.-H., and Tokhtar, V.K., Zur Sociologie von Arten der Gattung Oenothera L. im Rheintal von Arnheim (NL) bis Mülhouse (F), Tuexenia, 1999, vol. 19 , pp. 447-467.

Translated by N. Statsyuk 